Ind. Eng. Chem. Res. 2016

\title{
Experimental and Theoretical Thermodynamic Study of Distillable Ionic Liquid 1,5-Diazabicyclo[4.3.0]non-5-enium Acetate:
} Supporting Information

\author{
Alexandr Ostonen, ${ }^{1, *}$ Justine Bervas, ${ }^{1}$ Petri Uusi-Kyyny, ${ }^{1}$ Ville Alopaeus, ${ }^{1}$ Dzmitry $\mathbf{H}$. \\ Zaitsau, ${ }^{2}$ Vladimir N. Emel'yanenko, ${ }^{2}$ Christoph Schick, ${ }^{3}$ Alistair W. T. King, ${ }^{4}$ Jussi \\ Helminen, ${ }^{4}$ Ilkka Kilpeläinen, ${ }^{4}$ Artashes A. Khachatrian, ${ }^{5}$ Mikhail A. Varfolomeev, ${ }^{5}$ Sergey \\ P. Verevkin ${ }^{2} * *$ \\ ${ }^{1}$ Department of Biotechnology and Chemical Technology, Aalto University, Kemistintie 1, FI- \\ 00076, P.O. Box 16100, Espoo, Finland. \\ ${ }^{2}$ Institut für Chemie, Physikalische Chemie, Universität Rostock, Dr-Lorenz-Weg 1, 18059 \\ Rostock, Germany. \\ ${ }^{3}$ Institut für Physik, Polymerphysik, Universität Rostock, Albert-Einstein-Str. 23-24, 18051 \\ Rostock, Germany. \\ ${ }^{4}$ Department of Chemistry, University of Helsinki, A.I. Virtasen Aukio 1,FI-00014,P.O. Box 55, \\ Helsinki, Finland. \\ ${ }^{5}$ Department of Physical Chemistry, Kazan Federal University, Kremlevskaya str. 18, 420008 \\ Kazan, Russia
}

* To whom correspondence concerning the reaction and solution calorimetry measurements and data evaluation should be addressed, E-mail: alexandr.ostonen@aalto.fi (A. Ostonen)

**To whom correspondence concerning the thermodynamic measurements and data evaluation should be addressed, E-mail: sergey.verevkin@uni-rostock.de (S.P. Verevkin)

Keywords: ionic liquids; reaction calorimetry, solution calorimetry, combustion calorimetry; enthalpy of formation; quantum-chemical calculations 
Table S1. Provenance and Purity of Samples Used

\begin{tabular}{|c|c|c|c|c|c|c|c|}
\hline $\begin{array}{l}\text { Chemical } \\
\text { name }\end{array}$ & Source & $\begin{array}{c}\text { Initial mass } \\
\text { fraction purity }\end{array}$ & $\begin{array}{c}\text { Final mass } \\
\text { fraction purity }\end{array}$ & $\begin{array}{l}\text { Mass fraction } \\
\text { water content }\end{array}$ & $\begin{array}{c}\begin{array}{c}\text { Mole fraction of } \\
\text { APP/APPH }\end{array} \\
\end{array}$ & $\begin{array}{c}\text { Analysis } \\
\text { method }\end{array}$ & $\begin{array}{c}\begin{array}{c}\text { Purification } \\
\text { method }\end{array} \\
\end{array}$ \\
\hline Acetic acid & Sigma-Aldrich & - & $\geq 0.998$ & - & - & - & - \\
\hline $\mathrm{DBN}$ & Fluorochem & $\geq 0.990$ & $\geq 0.997$ & $\leq 0.0028$ & $\leq 0.0001$ & ${ }^{1} \mathrm{H}$ NMR, K-F & Distillation \\
\hline$[\mathrm{DBNH}][\mathrm{OAc}]$ & - & - & $\geq 0.989$ & $\leq 0.0003$ & $\leq 0.0095$ & ${ }^{1} \mathrm{H}$ NMR, K-F & - \\
\hline Chemical name & Source & $\begin{array}{c}\text { Initial mass } \\
\text { fraction purity }\end{array}$ & $\begin{array}{c}\text { Final mass } \\
\text { fraction purity }\end{array}$ & $\begin{array}{l}\text { Mass fraction } \\
\text { water content }\end{array}$ & $\begin{array}{c}\begin{array}{c}\text { Mole fraction of } \\
\text { APP/APPH }\end{array} \\
\end{array}$ & $\begin{array}{c}\text { Analysis } \\
\text { method }^{\text {a,b }}\end{array}$ & $\begin{array}{c}\begin{array}{c}\text { Purification } \\
\text { method }\end{array} \\
\end{array}$ \\
\hline Acetic acid & Sigma-Aldrich & - & $\geq 0.998$ & - & - & - & - \\
\hline $\mathrm{DBN}$ & Fluorochem & $\geq 0.990$ & $\geq 0.997$ & $\leq 0.0028$ & $\leq 0.0001$ & ${ }^{1} \mathrm{H}$ NMR, K-F & Distillation \\
\hline$[\mathrm{DBNH}][\mathrm{OAc}]$ & - & - & $\geq 0.989$ & $\leq 0.0003$ & $\leq 0.0095$ & ${ }^{1} \mathrm{H}$ NMR, K-F & - \\
\hline n-Octane & Sigma-Aldrich & $\geq 0.980$ & $\geq 0.980$ & $\leq 0.0002$ & - & GC, K-F & - \\
\hline n-Nonane & Sigma-Aldrich & $\geq 0.980$ & $\geq 0.980$ & $\leq 0.0002$ & - & $\mathrm{GC}, \mathrm{K}-\mathrm{F}$ & - \\
\hline n-Decane & Sigma-Aldrich & $\geq 0.980$ & $\geq 0.980$ & $\leq 0.0002$ & - & $\mathrm{GC}, \mathrm{K}-\mathrm{F}$ & - \\
\hline n-Undecane & Sigma-Aldrich & $\geq 0.980$ & $\geq 0.980$ & $\leq 0.0002$ & - & $\mathrm{GC}, \mathrm{K}-\mathrm{F}$ & - \\
\hline n-Dodecane & Sigma-Aldrich & $\geq 0.980$ & $\geq 0.980$ & $\leq 0.0002$ & - & $\mathrm{GC}, \mathrm{K}-\mathrm{F}$ & - \\
\hline Benzene & Sigma-Aldrich & $\geq 0.990$ & $\geq 0.996$ & $\leq 0.0003$ & - & $\mathrm{GC}, \mathrm{K}-\mathrm{F}$ & Distillation \\
\hline Toluene & Sigma-Aldrich & $\geq 0.980$ & $\geq 0.985$ & $\leq 0.0003$ & - & $\mathrm{GC}, \mathrm{K}-\mathrm{F}$ & Distillation \\
\hline Butylbenzene & Sigma-Aldrich & $\geq 0.980$ & $\geq 0.988$ & $\leq 0.0002$ & - & $\mathrm{GC}, \mathrm{K}-\mathrm{F}$ & Distillation \\
\hline Pentylbenzene & Sigma-Aldrich & $\geq 0.980$ & $\geq 0.989$ & $\leq 0.0002$ & - & $\mathrm{GC}, \mathrm{K}-\mathrm{F}$ & Distillation \\
\hline Methanol & Sigma-Aldrich & $\geq 0.980$ & $\geq 0.984$ & $\leq 0.0003$ & - & $\mathrm{GC}, \mathrm{K}-\mathrm{F}$ & Distillation \\
\hline Ethanol & Sigma-Aldrich & $\geq 0.980$ & $\geq 0.986$ & $\leq 0.0004$ & - & $\mathrm{GC}, \mathrm{K}-\mathrm{F}$ & Distillation \\
\hline 1-Propanol & Sigma-Aldrich & $\geq 0.980$ & $\geq 0.985$ & $\leq 0.0004$ & - & $\mathrm{GC}, \mathrm{K}-\mathrm{F}$ & Distillation \\
\hline 1-Butanol & Sigma-Aldrich & $\geq 0.980$ & $\geq 0.989$ & $\leq 0.0004$ & - & $\mathrm{GC}, \mathrm{K}-\mathrm{F}$ & Distillation \\
\hline 1-Pentanol & Sigma-Aldrich & $\geq 0.980$ & $\geq 0.985$ & $\leq 0.0004$ & - & $\mathrm{GC}, \mathrm{K}-\mathrm{F}$ & Distillation \\
\hline Acetone & Sigma-Aldrich & $\geq 0.990$ & $\geq 0.994$ & $\leq 0.0002$ & - & GC, K-F & Distillation \\
\hline Acetonitrile & Sigma-Aldrich & $\geq 0.990$ & $\geq 0.997$ & $\leq 0.0002$ & - & $\mathrm{GC}, \mathrm{K}-\mathrm{F}$ & Distillation \\
\hline Tetrahydrofuran & Sigma-Aldrich & $\geq 0.980$ & $\geq 0.987$ & $\leq 0.0002$ & - & $\mathrm{GC}, \mathrm{K}-\mathrm{F}$ & Distillation \\
\hline Dichloromethane & Sigma-Aldrich & $\geq 0.980$ & $\geq 0.988$ & $\leq 0.0002$ & - & $\mathrm{GC}, \mathrm{K}-\mathrm{F}$ & Distillation \\
\hline Trichloromethane & Sigma-Aldrich & $\geq 0.980$ & $\geq 0.989$ & $\leq 0.0002$ & - & $\mathrm{GC}, \mathrm{K}-\mathrm{F}$ & Distillation \\
\hline $\begin{array}{c}2,6- \\
\text { Dimethoxyphenol }\end{array}$ & Sigma-Aldrich & $\geq 0.980$ & $\geq 0.989$ & $\leq 0.0002$ & - & $\mathrm{GC}, \mathrm{K}-\mathrm{F}$ & Recrystallization \\
\hline $\begin{array}{c}1,2- \\
\text { Dihydroxybenzene }\end{array}$ & Sigma-Aldrich & $\geq 0.980$ & $\geq 0.987$ & $\leq 0.0002$ & - & $\mathrm{GC}, \mathrm{K}-\mathrm{F}$ & Recrystallization \\
\hline 3-Methoxyphenol & Sigma-Aldrich & $\geq 0.980$ & $\geq 0.988$ & $\leq 0.0003$ & - & $\mathrm{GC}, \mathrm{K}-\mathrm{F}$ & Distillation \\
\hline 4-Ethylphenol & Sigma-Aldrich & $\geq 0.980$ & $\geq 0.989$ & $\leq 0.0003$ & - & $\mathrm{GC}, \mathrm{K}-\mathrm{F}$ & Recrystallization \\
\hline
\end{tabular}

${ }^{a}$ GC-Gas chromatography analysis of compounds purity.

${ }^{\mathrm{b}} \mathrm{K}-\mathrm{F}$ - Karl-Fisher titration technic for determination of water content. 
Table S2. Measured Heat Capacities of DBN ${ }^{a}$

\begin{tabular}{|c|c|c|c|c|c|}
\hline \multicolumn{4}{|c|}{$C_{\mathrm{p}}(\mathrm{DBN}, \mathrm{liq})$} & \multicolumn{2}{|c|}{$C_{\mathrm{p}}(\mathrm{DBN}, \mathrm{liq})$} \\
\hline $\mathbf{T} / \mathbf{K}$ & $J \cdot K^{-1} \cdot g^{-1}$ & $\mathrm{~J} \cdot \mathrm{K}^{-1} \cdot \mathrm{mol}^{-1}$ & $\mathbf{T} / \mathbf{K}$ & $J \cdot K^{-1} \cdot g^{-1}$ & $\mathrm{~J} \cdot \mathrm{K}^{-1} \cdot \mathrm{mol}^{-1}$ \\
\hline 227.0 & 1.524 & 189.3 & 272.2 & 1.653 & 205.2 \\
\hline 227.0 & 1.523 & 189.2 & 278.0 & 1.668 & 207.1 \\
\hline 228.0 & 1.532 & 190.2 & 278.0 & 1.670 & 207.4 \\
\hline 228.1 & 1.535 & 190.6 & 279.0 & 1.667 & 207.0 \\
\hline 229.0 & 1.533 & 190.3 & 279.0 & 1.670 & 207.4 \\
\hline 229.0 & 1.545 & 191.9 & 280.0 & 1.672 & 207.6 \\
\hline 230.0 & 1.548 & 192.2 & 280.0 & 1.674 & 207.8 \\
\hline 230.0 & 1.536 & 190.7 & 281.0 & 1.679 & 208.5 \\
\hline 231.0 & 1.550 & 192.4 & 281.0 & 1.679 & 208.5 \\
\hline 231.0 & 1.539 & 191.1 & 282.0 & 1.685 & 209.2 \\
\hline 232.0 & 1.552 & 192.8 & 282.0 & 1.683 & 209.0 \\
\hline 232.0 & 1.545 & 191.8 & 283.0 & 1.684 & 209.1 \\
\hline 233.0 & 1.550 & 192.5 & 283.0 & 1.688 & 209.6 \\
\hline 233.0 & 1.552 & 192.8 & 284.0 & 1.694 & 210.4 \\
\hline 234.0 & 1.553 & 192.8 & 284.0 & 1.685 & 209.3 \\
\hline 234.0 & 1.556 & 193.2 & 285.0 & 1.688 & 209.6 \\
\hline 235.0 & 1.554 & 193.0 & 285.0 & 1.697 & 210.7 \\
\hline 235.0 & 1.557 & 193.3 & 286.0 & 1.690 & 209.8 \\
\hline 236.0 & 1.560 & 193.8 & 286.0 & 1.699 & 210.9 \\
\hline 236.1 & 1.555 & 193.1 & 287.0 & 1.691 & 210.0 \\
\hline 237.0 & 1.567 & 194.5 & 287.1 & 1.710 & 212.4 \\
\hline 237.0 & 1.562 & 194.0 & 288.0 & 1.713 & 212.8 \\
\hline 238.0 & 1.570 & 195.0 & 288.0 & 1.690 & 209.9 \\
\hline 238.0 & 1.570 & 195.0 & 289.0 & 1.718 & 213.4 \\
\hline 239.0 & 1.574 & 195.5 & 289.0 & 1.698 & 210.9 \\
\hline 239.0 & 1.568 & 194.7 & 290.0 & 1.724 & 214.1 \\
\hline 240.0 & 1.576 & 195.7 & 290.0 & 1.703 & 211.5 \\
\hline 240.0 & 1.583 & 196.6 & 291.0 & 1.730 & 214.9 \\
\hline 241.0 & 1.583 & 196.6 & 291.0 & 1.707 & 212.0 \\
\hline 241.0 & 1.576 & 195.7 & 292.0 & 1.732 & 215.1 \\
\hline 242.0 & 1.581 & 196.3 & 292.0 & 1.711 & 212.5 \\
\hline 242.0 & 1.581 & 196.3 & 293.0 & 1.735 & 215.5 \\
\hline 243.0 & 1.582 & 196.5 & 293.0 & 1.715 & 213.0 \\
\hline 243.0 & 1.583 & 196.6 & 294.0 & 1.740 & 216.1 \\
\hline 244.0 & 1.581 & 196.3 & 294.0 & 1.717 & 213.2 \\
\hline 244.0 & 1.585 & 196.8 & 295.0 & 1.745 & 216.7 \\
\hline 245.0 & 1.581 & 196.4 & 295.0 & 1.718 & 213.3 \\
\hline 245.0 & 1.589 & 197.3 & 296.0 & 1.747 & 217.0 \\
\hline 246.0 & 1.579 & 196.1 & 296.0 & 1.721 & 213.7 \\
\hline 246.0 & 1.589 & 197.3 & 297.0 & 1.752 & 217.6 \\
\hline 247.0 & 1.596 & 198.2 & 297.0 & 1.721 & 213.7 \\
\hline 247.1 & 1.597 & 198.3 & 298.0 & 1.758 & 218.3 \\
\hline 248.0 & 1.590 & 197.5 & 298.1 & 1.726 & 214.3 \\
\hline 248.0 & 1.590 & 197.4 & 299.0 & 1.730 & 214.8 \\
\hline 249.0 & 1.590 & 197.4 & 299.0 & 1.759 & 218.4 \\
\hline 249.0 & 1.601 & 198.8 & 300.0 & 1.733 & 215.2 \\
\hline 250.0 & 1.595 & 198.1 & 300.0 & 1.765 & 219.2 \\
\hline
\end{tabular}




\begin{tabular}{|c|c|c|c|c|c|}
\hline 250.0 & 1.599 & 198.6 & 301.0 & 1.734 & 215.3 \\
\hline 251.0 & 1.600 & 198.7 & 301.0 & 1.765 & 219.2 \\
\hline 251.0 & 1.598 & 198.4 & 302.0 & 1.733 & 215.2 \\
\hline 252.0 & 1.601 & 198.9 & 302.0 & 1.768 & 219.6 \\
\hline 252.0 & 1.596 & 198.2 & 303.0 & 1.734 & 215.4 \\
\hline 253.0 & 1.607 & 199.6 & 303.0 & 1.777 & 220.7 \\
\hline 253.0 & 1.597 & 198.3 & 304.0 & 1.741 & 216.1 \\
\hline 254.0 & 1.614 & 200.5 & 304.0 & 1.780 & 221.1 \\
\hline 254.0 & 1.596 & 198.2 & 305.0 & 1.780 & 221.1 \\
\hline 255.0 & 1.608 & 199.7 & 305.0 & 1.750 & 217.3 \\
\hline 255.1 & 1.597 & 198.3 & 306.0 & 1.778 & 220.8 \\
\hline 256.0 & 1.606 & 199.4 & 306.0 & 1.758 & 218.3 \\
\hline 256.0 & 1.601 & 198.8 & 307.0 & 1.778 & 220.8 \\
\hline 257.0 & 1.613 & 200.2 & 307.0 & 1.761 & 218.7 \\
\hline 257.0 & 1.606 & 199.4 & 308.0 & 1.782 & 221.3 \\
\hline 258.0 & 1.616 & 200.7 & 308.0 & 1.762 & 218.8 \\
\hline 258.0 & 1.610 & 199.9 & 309.0 & 1.786 & 221.8 \\
\hline 259.0 & 1.619 & 201.1 & 309.0 & 1.764 & 219.0 \\
\hline 259.0 & 1.612 & 200.2 & 310.0 & 1.790 & 222.3 \\
\hline 260.0 & 1.623 & 201.5 & 310.0 & 1.763 & 219.0 \\
\hline 260.0 & 1.620 & 201.1 & 311.0 & 1.797 & 223.1 \\
\hline 261.0 & 1.623 & 201.5 & 311.1 & 1.770 & 219.8 \\
\hline 261.0 & 1.621 & 201.3 & 312.0 & 1.804 & 224.0 \\
\hline 262.0 & 1.625 & 201.8 & 312.1 & 1.776 & 220.5 \\
\hline 262.0 & 1.624 & 201.7 & 313.0 & 1.804 & 224.0 \\
\hline 263.0 & 1.631 & 202.6 & 313.1 & 1.781 & 221.2 \\
\hline 263.0 & 1.626 & 201.9 & 314.0 & 1.784 & 221.5 \\
\hline 264.0 & 1.637 & 203.3 & 314.0 & 1.807 & 224.4 \\
\hline 264.0 & 1.626 & 201.9 & 315.0 & 1.812 & 225.0 \\
\hline 265.0 & 1.641 & 203.8 & 315.0 & 1.782 & 221.3 \\
\hline 265.0 & 1.628 & 202.1 & 316.0 & 1.814 & 225.3 \\
\hline 266.0 & 1.640 & 203.6 & 316.0 & 1.782 & 221.2 \\
\hline 266.0 & 1.629 & 202.3 & 317.0 & 1.814 & 225.3 \\
\hline 267.0 & 1.634 & 203.0 & 317.0 & 1.784 & 221.5 \\
\hline 267.0 & 1.644 & 204.1 & 318.0 & 1.819 & 225.8 \\
\hline 268.0 & 1.646 & 204.4 & 318.0 & 1.790 & 222.3 \\
\hline 268.0 & 1.639 & 203.5 & 319.0 & 1.816 & 225.6 \\
\hline 269.0 & 1.637 & 203.3 & 319.1 & 1.797 & 223.1 \\
\hline 269.0 & 1.646 & 204.4 & 320.0 & 1.796 & 223.0 \\
\hline 270.0 & 1.637 & 203.3 & 320.0 & 1.812 & 225.1 \\
\hline 270.0 & 1.646 & 204.4 & 321.0 & 1.813 & 225.1 \\
\hline 271.0 & 1.644 & 204.2 & 321.0 & 1.795 & 222.9 \\
\hline 271.0 & 1.650 & 204.9 & 322.0 & 1.813 & 225.1 \\
\hline 272.0 & 1.644 & 204.2 & 322.0 & 1.793 & 222.7 \\
\hline 272.0 & 1.653 & 205.2 & 322.4 & 1.813 & 225.2 \\
\hline 272.1 & 1.643 & 204.0 & 322.4 & 1.793 & 222.6 \\
\hline
\end{tabular}

${ }^{\text {a }} T$ is the temperature, $C_{\mathrm{p}}(\mathrm{DBN}$, liq) is the measured heat capacity of liquid DBN. 
Table S3. Measured Heat Capacities of [DBNH][OAc $]^{\mathrm{a}}$

\begin{tabular}{|c|c|c|c|c|c|}
\hline \multicolumn{4}{|c|}{$C_{\mathrm{p}}(\mathrm{IL}, \mathrm{liq})$} & \multicolumn{2}{|c|}{$C_{\mathrm{p}}(\mathrm{IL}, \mathrm{liq})$} \\
\hline $\mathbf{T} / \mathbf{K}$ & $\mathrm{J} \cdot \mathrm{K}^{-1} \cdot \mathrm{g}^{-1}$ & $\mathrm{~J} \cdot \mathrm{K}^{-1} \cdot \mathrm{mol}^{-1}$ & $\mathbf{T} / \mathrm{K}$ & $\mathrm{J} \cdot \mathrm{K}^{-1} \cdot \mathrm{g}^{-1}$ & $\mathrm{~J} \cdot \mathrm{K}^{-1} \cdot \mathrm{mol}^{-1}$ \\
\hline 278.5 & 1.865 & 343.6 & 325.3 & 2.097 & 386.4 \\
\hline 278.5 & 1.867 & 344.0 & 326.0 & 2.100 & 386.9 \\
\hline 279.2 & 1.867 & 344.0 & 326.7 & 2.103 & 387.5 \\
\hline 279.2 & 1.868 & 344.1 & 328.2 & 2.109 & 388.6 \\
\hline 280.2 & 1.873 & 345.1 & 329.2 & 2.113 & 389.2 \\
\hline 280.2 & 1.871 & 344.7 & 329.2 & 2.116 & 389.8 \\
\hline 281.2 & 1.877 & 345.8 & 330.2 & 2.115 & 389.7 \\
\hline 281.2 & 1.874 & 345.3 & 330.2 & 2.119 & 390.4 \\
\hline 282.2 & 1.880 & 346.3 & 331.1 & 2.122 & 390.9 \\
\hline 282.2 & 1.877 & 345.9 & 331.2 & 2.120 & 390.5 \\
\hline 283.2 & 1.883 & 346.9 & 332.2 & 2.127 & 391.8 \\
\hline 283.2 & 1.884 & 347.0 & 332.2 & 2.126 & 391.7 \\
\hline 284.2 & 1.886 & 347.5 & 333.2 & 2.132 & 392.7 \\
\hline 284.2 & 1.891 & 348.4 & 333.2 & 2.132 & 392.7 \\
\hline 285.2 & 1.889 & 348.0 & 334.2 & 2.138 & 393.9 \\
\hline 285.2 & 1.898 & 349.7 & 334.2 & 2.136 & 393.5 \\
\hline 286.2 & 1.894 & 349.0 & 335.2 & 2.143 & 394.8 \\
\hline 286.2 & 1.905 & 350.9 & 335.2 & 2.142 & 394.6 \\
\hline 287.2 & 1.901 & 350.2 & 336.2 & 2.147 & 395.6 \\
\hline 287.2 & 1.907 & 351.4 & 336.2 & 2.148 & 395.8 \\
\hline 288.2 & 1.911 & 352.0 & 337.1 & 2.154 & 396.8 \\
\hline 288.2 & 1.916 & 352.9 & 337.2 & 2.150 & 396.1 \\
\hline 289.2 & 1.908 & 351.4 & 338.1 & 2.154 & 396.7 \\
\hline 289.2 & 1.912 & 352.3 & 338.1 & 2.160 & 397.9 \\
\hline 290.2 & 1.912 & 352.2 & 339.1 & 2.160 & 398.0 \\
\hline 290.2 & 1.917 & 353.1 & 339.1 & 2.164 & 398.6 \\
\hline 291.2 & 1.916 & 353.0 & 340.2 & 2.168 & 399.4 \\
\hline 291.2 & 1.923 & 354.2 & 340.2 & 2.169 & 399.6 \\
\hline 292.2 & 1.921 & 354.0 & 341.2 & 2.175 & 400.7 \\
\hline 292.2 & 1.928 & 355.3 & 341.2 & 2.175 & 400.7 \\
\hline 293.2 & 1.929 & 355.3 & 342.2 & 2.177 & 401.1 \\
\hline 293.2 & 1.934 & 356.4 & 342.2 & 2.182 & 402.0 \\
\hline 294.1 & 1.941 & 357.6 & 343.2 & 2.176 & 401.0 \\
\hline 294.2 & 1.936 & 356.7 & 343.2 & 2.189 & 403.3 \\
\hline 295.1 & 1.949 & 359.1 & 344.2 & 2.176 & 400.8 \\
\hline 295.2 & 1.940 & 357.4 & 344.2 & 2.191 & 403.6 \\
\hline 296.1 & 1.954 & 359.9 & 345.1 & 2.195 & 404.3 \\
\hline 296.2 & 1.939 & 357.3 & 345.2 & 2.180 & 401.7 \\
\hline 297.2 & 1.959 & 360.9 & 346.1 & 2.187 & 403.0 \\
\hline 297.2 & 1.943 & 357.9 & 346.1 & 2.194 & 404.2 \\
\hline 298.2 & 1.965 & 362.1 & 347.2 & 2.194 & 404.2 \\
\hline 298.2 & 1.952 & 359.6 & 347.2 & 2.196 & 404.5 \\
\hline 299.2 & 1.960 & 361.0 & 348.2 & 2.198 & 405.0 \\
\hline 299.2 & 1.969 & 362.7 & 348.2 & 2.201 & 405.5 \\
\hline 300.2 & 1.963 & 361.7 & 349.2 & 2.202 & 405.7 \\
\hline 300.2 & 1.971 & 363.2 & 349.2 & 2.200 & 405.4 \\
\hline
\end{tabular}




\begin{tabular}{|c|c|c|c|c|c|}
\hline 301.2 & 1.965 & 362.1 & 350.2 & 2.202 & 405.7 \\
\hline 301.2 & 1.975 & 363.9 & 350.2 & 2.184 & 402.4 \\
\hline 302.2 & 1.970 & 362.8 & 351.2 & 2.203 & 405.9 \\
\hline 302.2 & 1.980 & 364.7 & 351.2 & 2.207 & 406.6 \\
\hline 303.2 & 1.974 & 363.7 & 352.1 & 2.220 & 409.0 \\
\hline 303.2 & 1.985 & 365.7 & 352.2 & 2.208 & 406.8 \\
\hline 304.2 & 1.979 & 364.6 & 353.1 & 2.216 & 408.3 \\
\hline 304.2 & 1.993 & 367.1 & 353.1 & 2.230 & 410.8 \\
\hline 305.2 & 1.985 & 365.7 & 354.1 & 2.222 & 409.4 \\
\hline 305.2 & 2.000 & 368.5 & 354.1 & 2.228 & 410.4 \\
\hline 306.2 & 1.992 & 366.9 & 355.2 & 2.230 & 410.8 \\
\hline 306.2 & 2.003 & 369.0 & 355.2 & 2.228 & 410.4 \\
\hline 307.2 & 1.995 & 367.6 & 356.2 & 2.237 & 412.1 \\
\hline 307.2 & 2.006 & 369.6 & 356.2 & 2.234 & 411.6 \\
\hline 308.1 & 1.998 & 368.0 & 357.2 & 2.247 & 414.0 \\
\hline 308.2 & 2.013 & 370.8 & 357.2 & 2.240 & 412.6 \\
\hline 309.1 & 2.003 & 368.9 & 358.2 & 2.245 & 413.7 \\
\hline 309.1 & 2.025 & 373.1 & 358.2 & 2.243 & 413.2 \\
\hline 310.1 & 2.008 & 369.9 & 359.2 & 2.245 & 413.5 \\
\hline 310.2 & 2.033 & 374.6 & 359.2 & 2.252 & 414.8 \\
\hline 311.2 & 2.013 & 370.8 & 360.2 & 2.246 & 413.7 \\
\hline 311.2 & 2.032 & 374.4 & 360.2 & 2.249 & 414.3 \\
\hline 312.2 & 2.021 & 372.3 & 361.1 & 2.247 & 414.0 \\
\hline 312.2 & 2.034 & 374.8 & 361.1 & 2.249 & 414.3 \\
\hline 313.2 & 2.027 & 373.4 & 362.1 & 2.256 & 415.6 \\
\hline 313.2 & 2.037 & 375.2 & 362.2 & 2.252 & 414.9 \\
\hline 314.2 & 2.031 & 374.1 & 363.2 & 2.262 & 416.8 \\
\hline 314.2 & 2.040 & 375.9 & 363.2 & 2.257 & 415.7 \\
\hline 315.2 & 2.034 & 374.7 & 364.2 & 2.268 & 417.8 \\
\hline 315.2 & 2.044 & 376.6 & 364.2 & 2.261 & 416.6 \\
\hline 316.2 & 2.042 & 376.3 & 365.2 & 2.270 & 418.1 \\
\hline 316.2 & 2.046 & 376.9 & 365.2 & 2.266 & 417.4 \\
\hline 317.1 & 2.048 & 377.4 & 366.2 & 2.270 & 418.1 \\
\hline 317.2 & 2.051 & 377.9 & 366.2 & 2.271 & 418.4 \\
\hline 318.1 & 2.046 & 376.9 & 367.2 & 2.275 & 419.1 \\
\hline 318.2 & 2.065 & 380.5 & 367.2 & 2.272 & 418.7 \\
\hline 319.2 & 2.057 & 379.0 & 368.2 & 2.279 & 419.9 \\
\hline 319.2 & 2.071 & 381.6 & 368.2 & 2.275 & 419.1 \\
\hline 320.2 & 2.067 & 380.8 & 369.1 & 2.285 & 420.9 \\
\hline 320.2 & 2.077 & 382.7 & 369.1 & 2.280 & 420.1 \\
\hline 321.2 & 2.074 & 382.0 & 370.1 & 2.286 & 421.2 \\
\hline 321.2 & 2.082 & 383.6 & 370.1 & 2.281 & 420.3 \\
\hline 322.2 & 2.080 & 383.1 & 371.2 & 2.288 & 421.6 \\
\hline 322.2 & 2.085 & 384.2 & 371.2 & 2.285 & 421.0 \\
\hline 322.5 & 2.081 & 383.3 & 372.2 & 2.285 & 421.0 \\
\hline 323.2 & 2.088 & 384.8 & 372.2 & 2.293 & 422.4 \\
\hline 324.6 & 2.094 & 385.8 & 373.1 & 2.295 & 422.8 \\
\hline
\end{tabular}



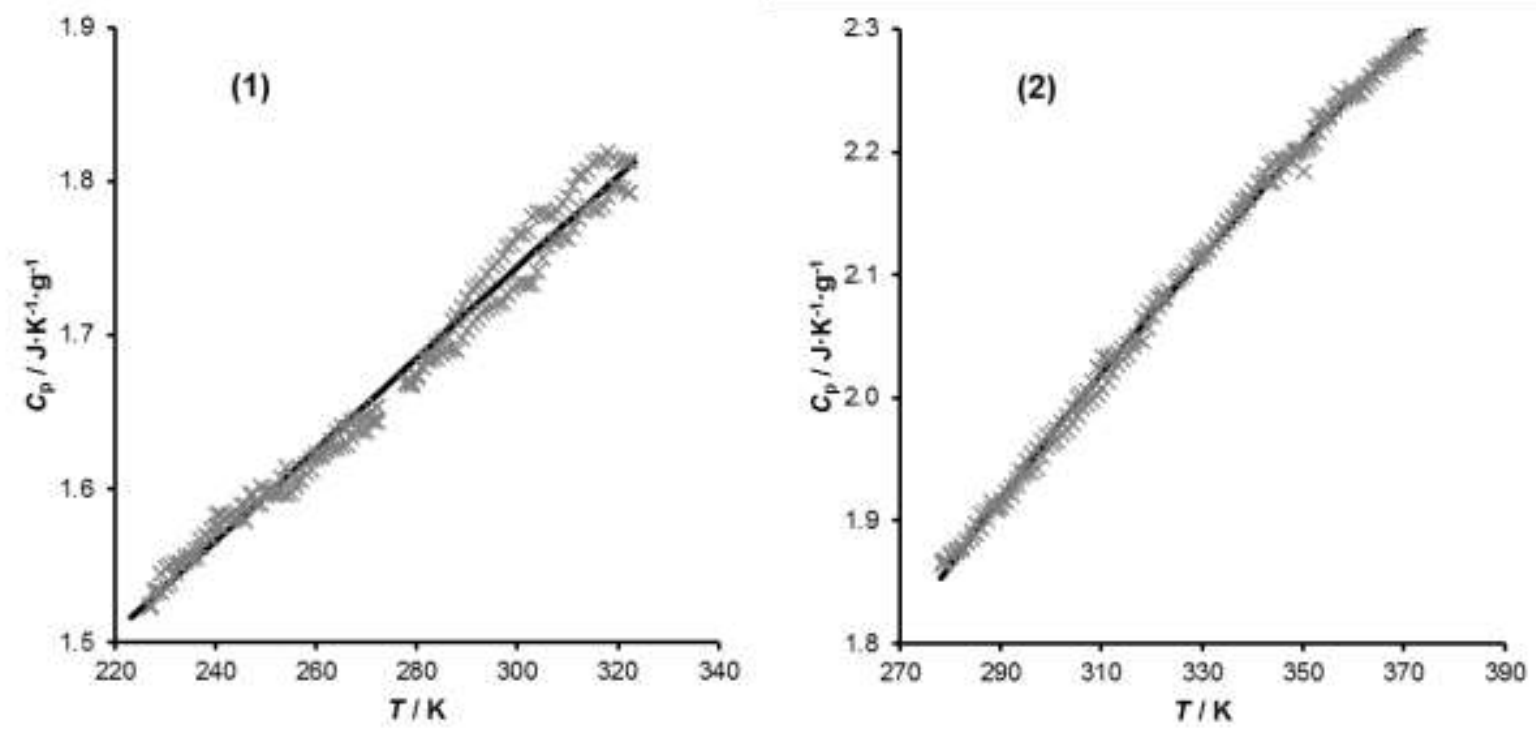

Figure S1. Experimental and smoothed heat capacities of DBN (1) and [DBNH][OAc] (2). Symbols: experimental data points; lines: correlation results.

Table S4. G4 Total Energies at $0 \mathrm{~K}$ and Enthalpies at 298.15 K (in Hartree) of the molecules Studied in This Work

\begin{tabular}{lccc}
\hline \multirow{2}{*}{ Compounds } & \multicolumn{3}{c}{$\mathrm{G} 4$} \\
\cline { 2 - 4 } & $E_{0}$ & $H_{298}$ & $\Delta_{\mathrm{f}} H_{\mathrm{m}}{ }^{\mathrm{a}}$ \\
\hline DBN & -383.208629 & -383.199778 & $66.7 \pm 3.5$ \\
Acetic acid & -228.982903 & -228.977339 & - \\
[DBNH][OAc] & -612.214166 & -612.199229 & $-421.9 \pm 3.5$ \\
\hline
\end{tabular}

${ }^{a}$ Calculated according to the atomization procedure and using the constant bias correction of 12.8 $\mathrm{kJ} \cdot \mathrm{mol}^{-1}$, derived from the G4 calculations reported by Suntsova and Dorofeeva. ${ }^{1}$ 
Table S5. Measured Enthalpies of Phase Transitions of [DBNH][OAc] ${ }^{\mathrm{a}}$

\begin{tabular}{ccc}
\hline Experiment & $T_{\text {trns }} / \mathrm{K}$ & $\begin{array}{c}\Delta_{\text {tms }} H_{\mathrm{m}}^{\circ} / \\
\mathrm{kJ} \cdot \mathrm{mol}^{-1}\end{array}$ \\
\hline 1 & 285.9 & 4.16 \\
& 317.5 & 11.50 \\
\hline 2 & 285.8 & 7.59 \\
& 317.5 & 10.4 \\
\hline $3-4^{\mathrm{b}}$ & 261.4 & 0.15 \\
& 272.9 & 0.47 \\
& 282.6 & 1.94 \\
& 292.4 & 0.70 \\
& 320.9 & 11.40 \\
\hline $5-12$ & 277.0 & 2.4 \\
& 315.1 & 13.8 \\
\hline
\end{tabular}

${ }^{\mathrm{a}} T_{\mathrm{trns}}$ is the phase transition onset temperature, $\Delta_{\mathrm{trns}} \mathrm{H}_{\mathrm{m}}^{\mathrm{o}}$ is the enthalpy of the phase transition.

${ }^{b}$ The reproducibility of the phase transition temperatures and the enthalpies of phase transition of experiments 3-4 were $\pm 1 \mathrm{~K}$ and $\pm 0.1 \mathrm{~kJ} \cdot \mathrm{mol}^{-1}$, respectively.

\section{DETAILS ON CALIBRATION AND MEASUREMENTS WITH THE PARR CALORIMETER}

The Parr calorimeter was calibrated by dissolution of tris-(hydroxymethyl)-aminomethane (TRIS) (mass fraction purity $\geq 0.998$ ) in $0.1 \mathrm{M} \mathrm{HCl}$ solution according to the recommendations provided by the manufacturer. ${ }^{2}$ The energy equivalent of the calorimeter was calculated according to Eqs. $\mathrm{S} 1$ and $\mathrm{S} 2$.

$$
\begin{aligned}
& \frac{e^{\prime}}{\mathrm{J} \cdot \mathrm{K}^{-1}}=\left(\frac{Q_{\mathrm{r}} / \mathrm{J}}{\Delta T / \mathrm{K}}-\frac{m(\mathrm{HCl})}{\mathrm{g}} \cdot \frac{C_{p}(\mathrm{HCl})}{\mathrm{J} \cdot(\mathrm{K} \cdot \mathrm{g})^{-1}}\right) \\
& \frac{Q_{\mathrm{r}}}{\mathrm{J}}=\frac{m(\mathrm{TRIS})}{\mathrm{g}} \cdot\left[245.760 \frac{\mathrm{J}}{\mathrm{g}}+1.4364 \frac{\mathrm{J}}{\mathrm{g} \cdot \mathrm{K}} \cdot\left(298.15 \mathrm{~K}-\frac{T(0.63)}{\mathrm{K}}\right)\right]
\end{aligned}
$$

where $e^{\prime}$ is the energy equivalent of the calorimeter, $Q_{\mathrm{r}}$ is the energy released from the reaction, $\Delta T$ is the net temperature rise due to the dissolution, $m(\mathrm{HCl})$ is the mass of the $0.1 \mathrm{M} \mathrm{HCl}$ solution, $C_{p}(\mathrm{HCl})$ is the heat capacity of the $0.1 \mathrm{M} \mathrm{HCl}$ solution at $298.15 \mathrm{~K}\left(4.17956 \mathrm{~J} \cdot \mathrm{K}^{-1} \cdot \mathrm{g}^{-1}\right)$, $m$ (TRIS) is the mass of the dissolved TRIS sample, $T(0.63)$ is the interpolated average reaction temperature at which the temperature has reached $63 \%$ of its total rise resulted from the reaction. 
The calculated energy equivalent at $298.15 \mathrm{~K}$ was $(112.1 \pm 5.1) \mathrm{J} \cdot \mathrm{K}^{-1}$. The calibration was checked with the $\mathrm{HCl}+\mathrm{NaOH}$ neutralization reaction. The obtained value was adjusted to the infinite dilution and $298.15 \mathrm{~K}$ temperature using values from refs 3 and 4, respectively. The adjusted value $-\left(55.75 \pm 0.54 \mathrm{~kJ} \cdot \mathrm{mol}^{-1}\right)$ agreed within determination uncertainty with the value recommended by the National Bureau of Standards $\left(-55.836 \mathrm{~kJ} \cdot \mathrm{mol}^{-1}\right){ }^{5}$ The results of the calibration experiments as well as the description of the adjustments are available in Table S6. A temperature profile of a typical calorimetric experiment is presented in Fig. S2.

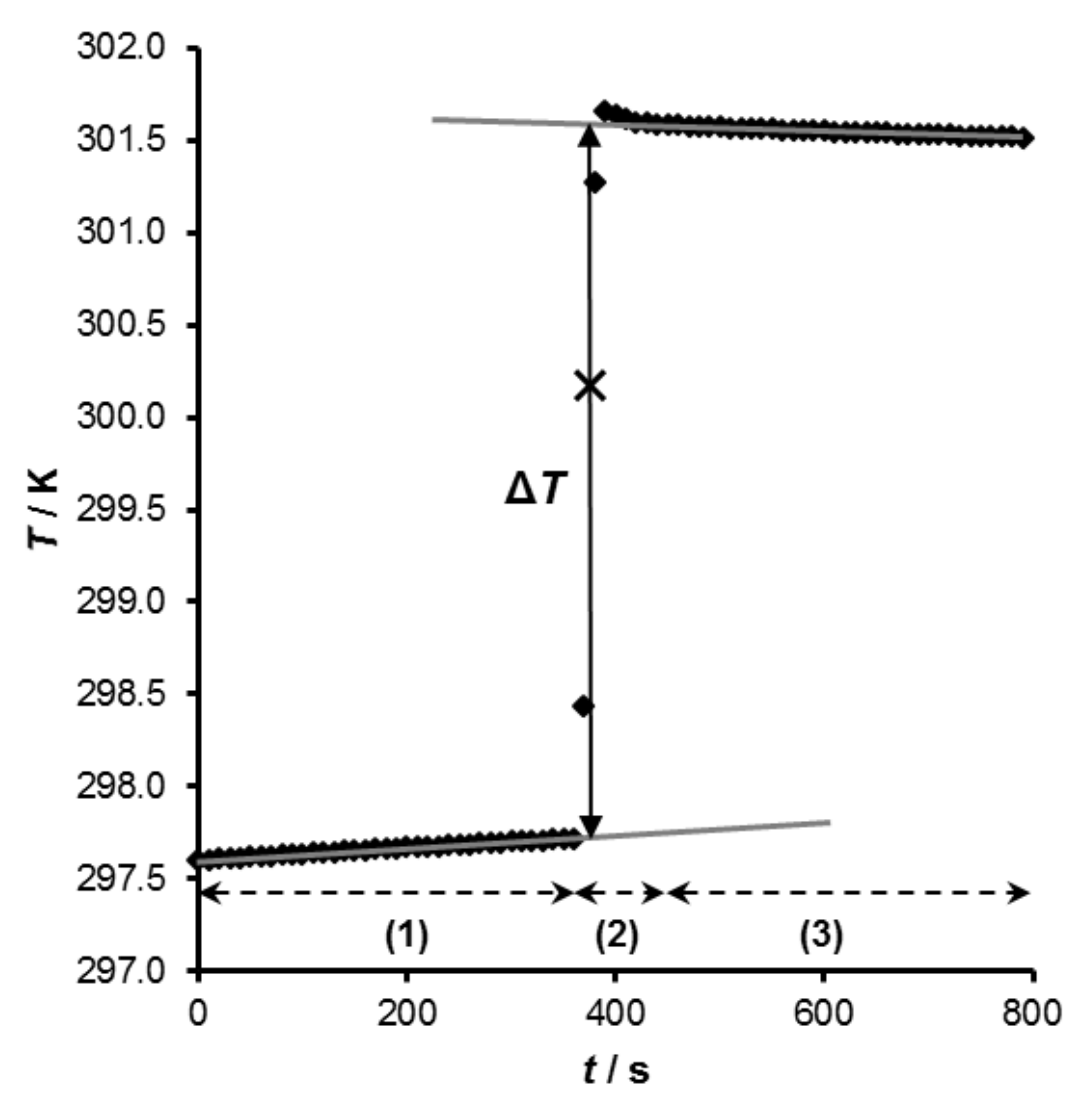

Figure S2. Temperature profile in a typical net [DBNH][OAc] synthesis reaction experiment. (1): initial period; (2): main period; (3): final period; $(x)$ : interpolated average reaction temperature at which the temperature has reached $63 \%$ of its total rise; ( $\bullet)$ : measured data points; Gray lines: extrapolations of the initial and final period points. 
Table S6. Calibration Results of Parr 6755 Solution Calorimeter $^{\mathrm{a}}$

\begin{tabular}{lccccc}
\hline Dissolution of TRIS in 0.1 M HCl solution & \\
\hline & 1 & 2 & 3 & 4 & 5 \\
\hline$m(\mathrm{TRIS}) / \mathrm{g}$ & 0.5009 & 0.5002 & 0.5010 & 0.5003 & 1.0002 \\
$m(0.1 \mathrm{M} \mathrm{HCl}) / \mathrm{g}$ & 100.0026 & 100.0010 & 100.0009 & 100.0026 & 100.0011 \\
$\Delta T / \mathrm{K}$ & 0.2354 & 0.2340 & 0.2378 & 0.2340 & 0.4657 \\
$T(0.63) / \mathrm{K}$ & 295.1695 & 294.9418 & 297.2860 & 296.3459 & 296.8235 \\
$Q_{\mathrm{r}} / \mathrm{J}$ & 125.25 & 125.23 & 123.75 & 124.25 & 247.71 \\
$e^{\prime} / \mathrm{J} \cdot \mathrm{K}^{-l}$ & 114.09 & 117.23 & 102.42 & 113.02 & 113.96 \\
\hline
\end{tabular}

Dissolution of $1 \mathrm{M} \mathrm{NaOH}$ in $0.1 \mathrm{M} \mathrm{HCl}^{\mathrm{e}}$

\begin{tabular}{lcccc}
\hline Experiment & 1 & 2 & 3 & 4 \\
\hline $\mathrm{m}(1 \mathrm{M} \mathrm{NaOH}) / \mathrm{g}$ & 0.9998 & 1.0010 & 2.0000 & 2.0001 \\
$\mathrm{n}(\mathrm{NaOH}) / \mathrm{mmol}$ & 0.9595 & 0.9607 & 1.9194 & 1.9195 \\
$\mathrm{~m}(0.1 \mathrm{M} \mathrm{HCl}) / \mathrm{g}$ & 100.0005 & 100.0022 & 100.0007 & 100.0015 \\
$\mathrm{n}(\mathrm{HCl}) / \mathrm{mmol}$ & 10.0201 & 10.0203 & 10.0201 & 10.0202 \\
$\Delta T / \mathrm{K}$ & 0.1030 & 0.1017 & 0.2082 & 0.2081 \\
$T(0.63) / \mathrm{K}$ & 295.5122 & 295.8784 & 296.1694 & 295.5217 \\
$\Delta_{\text {neut }} H_{\mathrm{m}}(x, \mathrm{~T}(0.63)) / \mathrm{kJ}^{-\mathrm{mol}^{-1 \mathrm{~b}}}$ & -56.90 & -56.12 & -57.50 & -57.47 \\
$\Delta_{\text {neut }} H_{\mathrm{m}}$ (inf, $\mathrm{T}(0.63) / \mathrm{kJ}^{-\mathrm{mol}^{-1 \mathrm{c}}}$ & -56.21 & -55.42 & -56.74 & -56.71 \\
$\Delta_{\text {neut }} H_{\mathrm{m}}^{\circ}$ (inf) / $\mathrm{kJ} \cdot \mathrm{mol}^{-1 \mathrm{~d}}$ & -55.63 & -54.92 & -56.31 & -56.13
\end{tabular}

a $m(i)$ and $n(i)$ are the mass and molar amounts of component $i, \Delta T$ is the temperature change resulted from the dissolution, $\mathrm{T}(0.63)$ is the interpolated temperature value at which the temperature has reached $63 \%$ of its total rise resulted from the reaction, $Q_{\mathrm{r}}$ is the energy released from the reaction, $e^{\prime}$ is the energy equivalent of the calorimeter, $\Delta_{\text {neut }} H_{\mathrm{m}}$ is the enthalpy of neutralization reaction, inf is the infinite dilution.

${ }^{\mathrm{b}} x(i)=n\left(\mathrm{H}_{2} \mathrm{O}\right) / \mathrm{n}(i)$

${ }^{\mathrm{c}} \Delta_{\text {neut }} H_{\mathrm{m}}(\inf , T(0.63))=\Delta_{\text {neut }} H_{\mathrm{m}}(x, T(0.63))-\Delta_{\mathrm{dil}} H_{\mathrm{m}}(\mathrm{HCl})-\Delta_{\mathrm{dil}} H_{\mathrm{m}}(\mathrm{NaOH})+\Delta_{\mathrm{dil}} H_{\mathrm{m}}(\mathrm{NaCl}) ;$

$\Delta_{\mathrm{dil}} H_{\mathrm{m}}(i)=\Delta_{\mathrm{f}} H_{m}^{\circ}(i, i n f)-\Delta_{\mathrm{f}} H_{m}^{\circ}(i, x(i))$

${ }^{\mathrm{d}} \Delta_{\text {neut }} H_{\mathrm{m}}^{\circ}$ (inf) $=\Delta_{\text {neut }} H_{\mathrm{m}}($ inf, $T(0.63))+\Delta_{\mathrm{r}} C_{\mathrm{p}} \cdot(298.15-T(0.63))$

e sample information: tris(hydroxymethyl)aminomethane (TRIS, mass fraction purity $\geq 0.998$ ), $0.1 \mathrm{M} \mathrm{HCl}$ and $1 \mathrm{M} \mathrm{NaOH}$ were purchased from Sigma-Aldrich. 
The total duration of an experiment was approximately 30 minutes. Stable baselines before and after the sample mixing are required during the experiment to achieve reliable and repeatable results. Therefore, the calorimeter was placed in a constant temperature room in order to maintain stable conditions during the experiments despite the lack of a thermostat in the calorimeter. The room temperature was $294.5-299.5 \mathrm{~K}$ over 60 days with $\pm 0.5 \mathrm{~K}$ deviation over 24 hours while the relative humidity was $44.5 \pm 0.1 \%$. The stable room temperature was beneficial for keeping the baseline of the calorimeter stable during the experiments. In addition, the stirring was started 90 minutes prior to the beginning of each experiment to stabilize the baselines. The enthalpy of reaction 1 (Eq. 1) at temperature $T$ was calculated according to Eq. S3:

$\Delta_{\mathrm{r}} H_{\mathrm{m}}((1), \operatorname{liq}, T)=\frac{\left(C_{\mathrm{p}}^{\mathrm{o}}(\mathrm{DBN}) \cdot n(\mathrm{DBN})+e^{\prime}\right) \cdot \Delta T}{n(\mathrm{HAc})}$

and adjusted to $298.15 \mathrm{~K}$ according to Eq S4:

$\Delta_{\mathrm{r}} H_{\mathrm{m}}^{\circ}(1)=\Delta_{\mathrm{r}} H_{\mathrm{m}}((1)$, liq,$T)+\Delta_{\mathrm{r}} C_{\mathrm{p}, \mathrm{m}}^{\circ} \cdot(298.15 \mathrm{~K}-T)$

The value $\Delta_{\mathrm{r}} C_{\mathrm{p}, \mathrm{m}}^{\circ}(298.15 \mathrm{~K})=22 \mathrm{~J} \cdot \mathrm{mol}^{-1} \cdot \mathrm{K}^{-1}$ was used in Eq $\mathrm{S} 4$. It was calculated from heat capacities of the reaction participants DBN $\left(216 \mathrm{~J} \cdot \mathrm{mol}^{-1} \cdot \mathrm{K}^{-1}\right)$, acetic acid $\left(123.1 \mathrm{~J} \cdot \mathrm{mol}^{-1} \cdot \mathrm{K}^{-1}\right)^{6}$ and [DBNH][OAc] $\left(361 \mathrm{~J} \cdot \mathrm{mol}^{-1} \cdot \mathrm{K}^{-1}\right)$ at $298.15 \mathrm{~K}$. The resulting enthalpy of reaction was $\Delta_{\mathrm{r}} H_{\mathrm{m}}^{\circ}(1)=-(44.6 \pm 0.7) \mathrm{kJ} \cdot \mathrm{mol}^{-1}$.

Table S7. Measured Enthalpies of the liquid phase [DBNH][OAc] Synthesis Reaction ${ }^{\mathrm{a}}$

\begin{tabular}{lcccc}
\hline Experiment & $\mathbf{1}$ & $\mathbf{2}$ & $\mathbf{3}$ & $\mathbf{4}$ \\
\hline$m(\mathrm{DBN}) / \mathrm{g}$ & 100.0061 & 100.0038 & 100.1612 & 100.0055 \\
$m(\mathrm{HOAc}) / \mathrm{g}$ & 1.0026 & 1.5002 & 1.5009 & 1.5001 \\
$\Delta T / \mathrm{K}$ & 2.6469 & 3.9231 & 3.782 & 3.8922 \\
$T(0.63) / \mathrm{K}$ & 301.0246 & 300.6459 & 302.3831 & 300.1791 \\
$\Delta_{\mathrm{r}} H_{\mathrm{m}}((1)$, liq, $T(0.63)) / \mathrm{kJ} \cdot \mathrm{mol}^{-1}$ & -45.34 & -44.91 & -43.32 & -44.56 \\
$\Delta_{\mathrm{r}} H_{\mathrm{m}}^{\circ}((1)$, liq $) / \mathrm{kJ} \cdot \mathrm{mol}^{-1}$ & -45.41 & -44.97 & -43.41 & -44.61 \\
\cline { 2 - 5 }$\Delta_{\mathrm{r}} H_{\mathrm{m}}^{\circ}((1)$, liq $) / \mathrm{kJ} \cdot \mathrm{mol}^{-1}($ average $)$ & \multicolumn{4}{c}{$-44.60 \pm 0.74$} \\
${ }^{\mathrm{a}} m(i)$ is the mass of $\mathrm{compound} i, \Delta T$ is the temperature rise resulted from the reaction, $T(0.63)$ is \\
the interpolated average reaction temperature at which the temperature has reached $63 \%$ of its \\
total rise resulted from the reaction, $\Delta_{\mathrm{r}} H_{\mathrm{m}}(1)$ is the enthalpy of the net [DBNH][OAc] synthesis \\
reaction.
\end{tabular}




\section{ENTHALPIES OF SOLUTION OF DBN AND [DBNH][OAc] IN WATER}

The results of the solution enthalpy measurements of [DBNH][OAc] DBN and in water or water + HOAc solutions are presented in Tables S8 and S9, respectively. Some details on solution calorimetry experiments are worth mentioning. By the dissolving of DBN in pure water, the measured value $\Delta_{\text {sol }} H_{\mathrm{m}}^{\circ}(I V)=-39.5 \pm 0.3 \mathrm{~kJ} \cdot \mathrm{mol}^{-1}$ was significantly less negative than $\Delta_{\text {sol }} H_{\mathrm{m}}^{\circ}(V)$ $=-53.4 \pm 0.7 \mathrm{~kJ} \cdot \mathrm{mol}^{-1}$ which was measured in the water+acetic acid solutions. This difference is due to the additional chemical reaction. For comparison, an enthalpy of neutralization reaction between a strong base and acetic acid, of $-54.3 \mathrm{~kJ} \cdot \mathrm{mol}^{-1}$ for the system $\mathrm{NaOH}+$ acetic acid at $293.15 \mathrm{~K}^{7}$ is in a good agreement with $\Delta_{\text {sol }} H_{\mathrm{m}}^{\circ}(V)$ determined in this work. As seen from Figure $\mathrm{S} 3$, the enthalpy of solution of DBN in water $+\mathrm{HOAc}$ solutions remains constant $\left(\Delta_{\mathrm{sol}} H_{\mathrm{m}}^{\circ}(I I I)\right)=$ $-92.9 \pm 0.7 \mathrm{~kJ} \cdot \mathrm{mol}^{-1}$ ) when the HOAc:DBN mole ratio is $1: 1$ or higher. Therefore, the complexes of $[\mathrm{DBNH}][\mathrm{OAc}]$ observed in the liquid phase experiments are not formed in the aqueous solution. Moreover, this observation suggests that the complexes are formed due to dimerization of acetic acid, not by the second protonation of DBN.

\section{Table S8. Measured Enthalpies of Solution of Crystalline [DBNH][OAc] in Water ${ }^{\mathrm{a}}$}

\begin{tabular}{ccccc}
\hline \multicolumn{5}{l}{ Solid [DBNH][OAc] dissolution in water } \\
\hline experiment \# & $m(\mathrm{IL}) / \mathrm{mg}$ & $n(\mathrm{IL}) / \mathrm{mmol}$ & $m\left(\mathrm{H}_{2} \mathrm{O}\right) / \mathrm{g}$ & $\Delta_{\mathrm{sol}} H_{\mathrm{m}}^{\circ}(I) / \mathrm{kJ}^{\prime} \mathrm{mol}^{-1}$ \\
\hline 1 & 39.80 & 0.2160 & 25.5492 & -41.25 \\
2 & 29.83 & 0.1619 & 25.2320 & -41.62 \\
3 & 88.09 & 0.4782 & 25.2868 & -41.45 \\
4 & 38.53 & 0.2091 & 25.1852 & -40.90 \\
5 & 57.48 & 0.3120 & 25.1546 & -40.13 \\
\cline { 2 - 4 } & & & Average & $-41.07 \pm 0.53$
\end{tabular}

${ }^{\mathrm{a}} m(\mathrm{IL})$ is the mass of the [DBNH][OAc]sample, $n(\mathrm{IL})$ is the molar amount of the [DBNH][OAc] sample, $m\left(\mathrm{H}_{2} \mathrm{O}\right)$ is the mass of water in the cell, $\Delta_{\mathrm{sol}} H_{\mathrm{m}}^{\circ}(I)$ is the enthalpy of solution of crystalline $[\mathrm{DBNH}][\mathrm{OAc}]$ in water. 
Table S9. Measured Enthalpies of Solution of DBN in Water and Water + Acetic Acid Solutions $^{\text {a }}$

\begin{tabular}{|c|c|c|c|c|c|c|c|}
\hline \multicolumn{8}{|c|}{ DBN dissolution in water + acetic acid solutions } \\
\hline experiment \# & $\begin{array}{c}m(\mathrm{DBN}) \\
/ \mathrm{mg}\end{array}$ & $\begin{array}{c}n(\mathrm{DBN}) \\
/ \mathrm{mmol}\end{array}$ & $\begin{array}{l}m(\mathrm{HOAc}) \\
/ \mathrm{mg}\end{array}$ & $\begin{array}{l}n(\mathrm{HOAc}) \\
/ \mathrm{mmol}\end{array}$ & $\begin{array}{c}m\left(\mathrm{H}_{2} \mathrm{O}\right) \\
/ \mathrm{g}\end{array}$ & $n(\mathrm{HOAc}) / n(\mathrm{DBN})$ & $\Delta_{\mathrm{sol}} H_{\mathrm{m}}^{\circ}\left(\mathrm{kJ} \cdot \mathrm{mol}^{-1}\right.$ \\
\hline 1 & 32.67 & 0.2631 & 5.27 & 0.0877 & 24.7836 & 0.33 & -58.24 \\
\hline 2 & 33.81 & 0.2723 & 8.18 & 0.1362 & 24.8544 & 0.50 & -67.53 \\
\hline 3 & 57.91 & 0.4663 & 25.46 & 0.4239 & 25.2339 & 0.91 & -89.39 \\
\hline 4 & 62.50 & 0.5033 & 29.75 & 0.4954 & 24.9206 & 0.98 & -93.04 \\
\hline 5 & 60.59 & 0.4879 & 30.08 & 0.5010 & 25.1986 & 1.03 & -92.72 \\
\hline 6 & 62.53 & 0.5035 & 30.27 & 0.5041 & 25.3576 & 1.00 & -92.20 \\
\hline 7 & 63.50 & 0.5114 & 30.26 & 0.5038 & 25.3425 & 0.99 & -94.22 \\
\hline 8 & 48.61 & 0.3914 & 25.86 & 0.4306 & 24.9031 & 1.10 & -93.87 \\
\hline 9 & 30.84 & 0.2483 & 29.82 & 0.4966 & 24.9785 & 2.00 & -92.23 \\
\hline 10 & 31.88 & 0.2567 & 30.84 & 0.5135 & 25.8311 & 2.00 & -92.29 \\
\hline \multirow[t]{2}{*}{11} & 19.45 & 0.1566 & 28.21 & 0.4698 & 24.9879 & 3.00 & -92.83 \\
\hline & & & & & & Average & $-92.92 \pm 0.71$ \\
\hline
\end{tabular}

DBN dissolution in water

\begin{tabular}{ccccc}
\hline experiment \# & $\begin{array}{c}m(\mathrm{DBN}) \\
/ \mathrm{mg}\end{array}$ & $\begin{array}{c}n(\mathrm{DBN}) \\
/ \mathrm{mmol}\end{array}$ & $\begin{array}{c}m\left(\mathrm{H}_{2} \mathrm{O}\right) \\
/ \mathrm{g}\end{array}$ & $\begin{array}{c}\Delta_{\mathrm{sol}} H_{\mathrm{m}}^{\circ} \\
/ \mathrm{kJ} \cdot \mathrm{mol}^{-1}\end{array}$ \\
\hline 1 & 148.50 & 1.1958 & 25.7292 & -39.07 \\
2 & 76.75 & 0.6181 & 25.0536 & -39.65 \\
3 & 69.75 & 0.5617 & 25.2523 & -39.35 \\
4 & 34.77 & 0.2800 & 24.9978 & -39.89 \\
\cline { 2 - 4 } & & & & Average \\
\hline
\end{tabular}

${ }^{\mathrm{a}} m(i)$ is the mass of component $i, n(i)$ is the molar amount of component $i, n(\mathrm{HOAc}) / n(\mathrm{DBN})$ is the mole ratio of acetic acid and DBN, $\Delta_{\text {sol }} H_{\mathrm{m}}^{\circ}(I I I)$ is the enthalpy of solution of liquid DBN in water + acetic acid solution, $\Delta_{\text {sol }} H_{\mathrm{m}}^{\circ}(I V)$ is the enthalpy of solution of liquid DBN in water. 


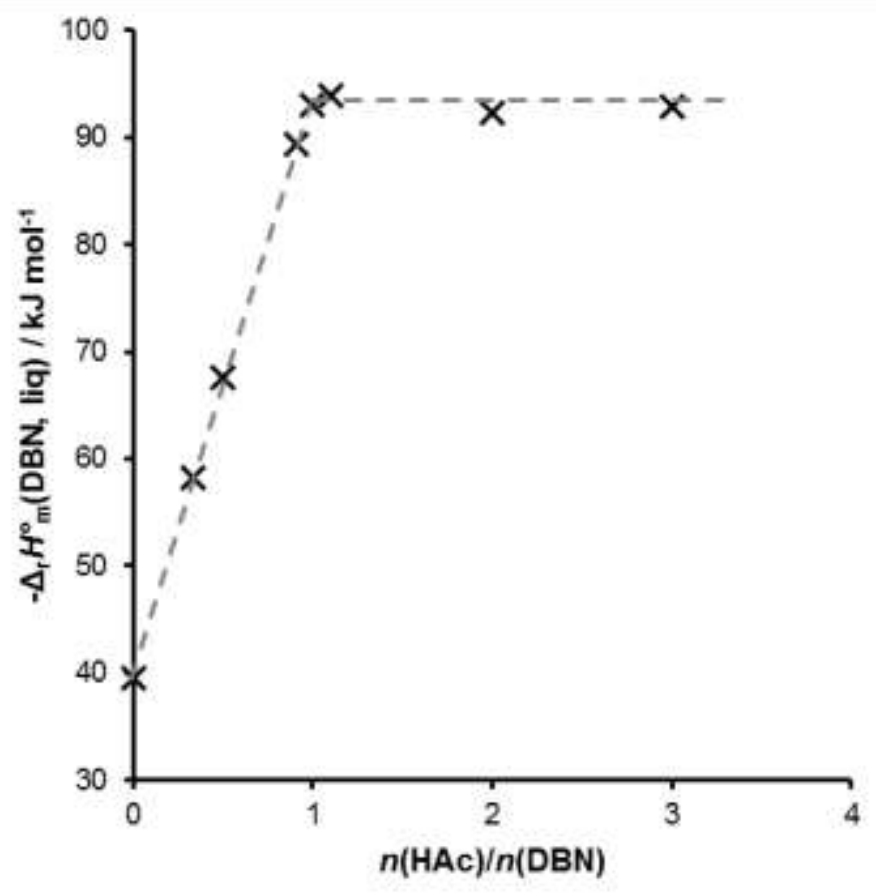

Figure S3. Enthalpy of solution of DBN in water and water + acetic acid solutions. 
Table S10. GC Results for Infinite Dilution Activity Coefficients (298.15 K), Solution Enthalpies (298.15 K) and Regressed Parameters of Organic Solvents in [DBNH][OAc] ${ }^{\mathrm{a}}$

\begin{tabular}{|c|c|c|c|c|c|}
\hline Solute $i$ & $\begin{array}{l}\text { Temperature } \\
\text { interval }(\mathrm{K})\end{array}$ & $a$ & $b(K)$ & $\gamma_{i}^{\infty}$ & $\Delta_{\mathrm{sol}} H_{\mathrm{m}}^{\mathrm{A} / \mathrm{IL}} / \mathrm{kJ} \cdot \mathrm{mol}^{-1}$ \\
\hline \multicolumn{6}{|l|}{ alkanes } \\
\hline decane & $303-323$ & 3.1751 & 890.8 & 474.85 & 7.40 \\
\hline undecane & $303-323$ & 3.4312 & 1084.6 & 1174.93 & 9.02 \\
\hline dodecane & $303-323$ & 3.4211 & 1239.2 & 1953.54 & 10.30 \\
\hline \multicolumn{6}{|l|}{ alkenes } \\
\hline 1-decene & $303-323$ & 3.6065 & 740.73 & 441.83 & 6.16 \\
\hline 1-dodecene & $303-323$ & 3.9653 & 919.77 & 1153.12 & 7.65 \\
\hline \multicolumn{6}{|l|}{ alkylbenzene } \\
\hline butylbenzene & $303-323$ & 2.3952 & 194.87 & 21.09 & 1.62 \\
\hline pentylbenzene & $303-323$ & 3.5131 & 227.88 & 72.05 & 1.89 \\
\hline \multicolumn{6}{|l|}{ alcohols } \\
\hline methanol & $303-323$ & -0.8708 & 156.3 & 0.71 & 1.30 \\
\hline ethanol & $303-323$ & -1.0409 & 356.65 & 1.17 & 2.97 \\
\hline 1-propanol & $303-323$ & -0.5926 & 409.89 & 2.19 & 3.41 \\
\hline 1-butanol & $303-323$ & -0.7076 & 596.65 & 3.63 & 4.96 \\
\hline 1-pentanol & $303-323$ & -0.4374 & 760.75 & 8.28 & 6.32 \\
\hline \multicolumn{6}{|l|}{ polar solvents } \\
\hline Acetone & $303-323$ & -0.3357 & 108.62 & 1.03 & 0.90 \\
\hline Acetonitrile & $303-323$ & -0.073 & -272.08 & 0.43 & -2.26 \\
\hline Tetrahydrofuran & $303-323$ & 0.296 & -617.07 & 0.17 & -5.13 \\
\hline Dichloromethane & $303-323$ & 6.0302 & -1848 & 0.85 & -15.36 \\
\hline Trichloromethane & $303-323$ & 8.607 & -2313.4 & 0.84 & -19.23 \\
\hline
\end{tabular}

a $a-b$ are the regressed parameters for Eq. $17, \gamma_{i}^{\infty}$ is the infinite dilution activity coefficient of compound $i, \Delta_{\mathrm{sol}} H_{\mathrm{m}}^{\mathrm{A} / \mathrm{IL}}$ is the enthalpy of partial molar excess enthalpy at infinite dilution of compound $i$. 


\section{DETAILS ON GC MEASUREMENTS OF ACTIVITY COEFFICIENTS}

Chromosorb W/AW-DMCS 100/120 mesh was used as solid support for the ionic liquid in the GC column. The chromosorb has been subjected to vacuum treatment with heating in order to remove traces of adsorbed moisture.

Coating the solid support material with the ionic liquid was performed by dispersing a certain portion of chromosorb in a solution of the ionic liquid in dichloromethane followed by evaporation of the solvent using a rotating evaporator. The chromosorb was weighed before and after the coating process. The experiments were performed with a Hewlett Packard gaschromatograph equipped with a flame ionization detector. Nitrogen was used as carrier gas. GC column (stainless steel) with length $45 \mathrm{~cm}$ with an inside diameter of $0.40 \mathrm{~cm}$ was used. The amount of stationary phase (ionic liquid) was around $5.4 \mathrm{mmol}$. The mass of the stationary phase was determined with a precision of $\pm 0.0003 \mathrm{~g}$. In order to avoid possible residual adsorption effects of the solutes on chromosorb, the amount of ionic liquid was about 35 mass per cent of the support material.

According to Cruickshank et al. ${ }^{8}$ the following equation for the data treatment was used:

$\ln \gamma_{i, 3}^{\infty}=\ln \left(\frac{n_{3} \cdot R \cdot T}{V_{N} \cdot p_{1}^{0}}\right)-\frac{B_{11}-V_{1}^{0}}{R T} \cdot p_{1}^{0}+\frac{2 \cdot B_{12}-V_{1}^{\infty}}{R T} \cdot J \cdot p_{0}$

where $\gamma_{i, 3}^{\infty}$ is the activity coefficient of component $i$ at infinite dilution in the stationary phase (index 3), $p_{1}^{0}$ is the vapor pressure of the pure liquid solute, $n_{3}$ is the number of moles of the stationary phase component (ionic liquid) on the column and $V_{\mathrm{N}}$ is the standardized retention volume obtained by:

$V_{N}=J \cdot U_{0} \cdot\left(t_{r}-t_{G}\right) \cdot \frac{T_{c o l}}{T_{f}} \cdot\left[1-\frac{p_{0 w}}{p_{o}}\right]$

where $t_{\mathrm{r}}$ is the retention time, $t_{\mathrm{G}}$ is the dead time, and $U_{0}$ is the flow rate, measured by a soap bubble flowmeter, $T_{\mathrm{col}}$ is the column temperature, $T_{f}$ is flowmeter temperature, $p_{\mathrm{ow}}$ is saturation pressure of water at $T_{f}, p_{\mathrm{o}}$ is the pressure at the column outlet.

The second and third term in Eq. S5 are correction terms which arise from the nonideality of mobile gaseous phase. $B_{11}$ is the second virial coefficient of the solute, $B_{12}$ the mixed 
virial coefficient of the solute (1) with the carrier gas nitrogen (2). $V_{1}^{0}$ is the liquid molar volume of pure solute and $V_{1}^{\infty}$ is the partial molar volume of solute in the ionic liquid at infinite dilution.

The factor $J$ appearing in Eqs. S5 and S6 corrects for the influence of the pressure drop along the column given by':

$$
J=\frac{3}{2} \cdot \frac{\left(p_{i} / p_{0}\right)^{2}-1}{\left(p_{i} / p_{0}\right)^{3}-1}
$$

where $p_{\mathrm{i}}$ and $p_{\mathrm{o}}$ are the inlet and the outlet pressure of the GC column respectively.

The outlet pressure $p_{\mathrm{o}}$ was kept equal to the atmospheric pressure. The pressure drop ( $p_{\mathrm{i}}$ $p_{\mathrm{o}}$ ) was varied between (20.3 and $101.3 \mathrm{kPa}$ ), providing suitable retention times with sharp peaks. The pressure drop and the outlet pressure were measured using a membrane manometer with an uncertainty of $\pm 0.2 \mathrm{kPa}$.

Volumes of the samples injected into the GC probes were $(0.5$ to $2 \mu l)$. No differences in retention times $t_{\mathrm{r}}$ were found by injecting individual pure components or their mixtures. This fact indicates that different concentrations of the solute in the stationary phase caused by different ratios of the injected amounts of solute and the amount of stationary phase do not affect the results and it can be concluded that in all cases the state of infinite dilution was realised to a high degree of approximation. Experiments were carried out at 4 to 5 temperatures between $303 \mathrm{~K}$ and $353 \mathrm{~K}$. The temperature of the GC column was maintained constant to within $\pm 0.01 \mathrm{~K}$. At a given temperature each experiment was repeated at least twice to check the reproducibility. Retention times were generally reproducible within (0.01 to 0.03$) \mathrm{min}$. Absolute values of retention times varied between (3 to 30) min depending on the individual solute. At each temperature values of the dead time $t_{G}$ identical to the retention time of a non-retainable component were measured. While our GC was equipped with a flame-ionization detector, methane ${ }^{8}$ was used as nonretainable component under the assumption that the effect of solubility of methane in ionic liquid is negligible. This assumption has been justified by attestation of our experimental procedure with the reliable data on $\gamma_{i}^{\infty}$ of hexane, heptane and benzene in hexadecane. ${ }^{10}$

In order to check the stability of the experimental conditions, such as the possible elution of the stationary phase by the nitrogen stream, the measurements of retention times were repeated systematically every ( 2 to 3 ) hours for tridecane. No changes of the retention times were observed during 2-3 days of continuous operation. 
Data needed for calculating the correction terms in Eq. S5 have been obtained in the following way. Molar volumes of solutes $V_{1}^{0}$ were estimated using experimental values of their densities, partial molar volumes of solute at infinite dilution $V_{1}^{\infty}$ have been assumed to be equal of $V_{1}^{0}$. Values of $B_{11}$ have been estimated according to Tsonopolous' method. ${ }^{11}$ Critical $^{\prime}$ parameters needed for the calculations were available from the literature. ${ }^{12}$ If these data were not available, values of the critical pressure $P_{\mathrm{c}}$, the critical temperature $T_{\mathrm{c}}$, and the critical volume $V_{\mathrm{c}}$ were estimated using Lydersen`s method. ${ }^{13}$ Acentric factors $\omega_{1}$ were calculated by Edmister equation. ${ }^{9}$ Values of $B_{12}$ have also been estimated according to Tsonopolous' method. The mixed critical properties $P_{\text {cij }}, T_{\text {cij }}, V_{\text {cij }}, Z_{\text {cij }}$ and mixed acentric factor $\omega_{\mathrm{ij}}$ were calculated by equations given in the literature. ${ }^{11,14}$

Values of vapor pressures $p_{1}^{0}$ of pure solutes are of a crucial importance for the reliability of $\gamma_{i}^{\infty}$. For alkanes these values were calculated using parameters of the Cox equation recommended by Ruzicka and Majer. ${ }^{15}$ For alkenes values of $p_{1}^{0}$ were calculated using parameters of the Cox equation recommended by Steele and Chirico. ${ }^{16}$ Vapor pressures of pure alcohols were calculated using coefficients of Wagner's equation recommended by Ambrose and Walton ${ }^{17}$. Specification of the sources of vapor pressures of other solutes was given in the previous papers of this series. ${ }^{18-19}$

The validity of the experimental procedure has been checked by comparison of our measured values of $\gamma_{i}^{\infty}$ for hexane in hexadecane with those available in the literature. ${ }^{10}$ The procedure of the experimental error estimation was described in our previous work. ${ }^{10}$ Values of $\gamma_{i}^{\infty}$ are estimated to be accurate within to $\pm 3 \%$. 


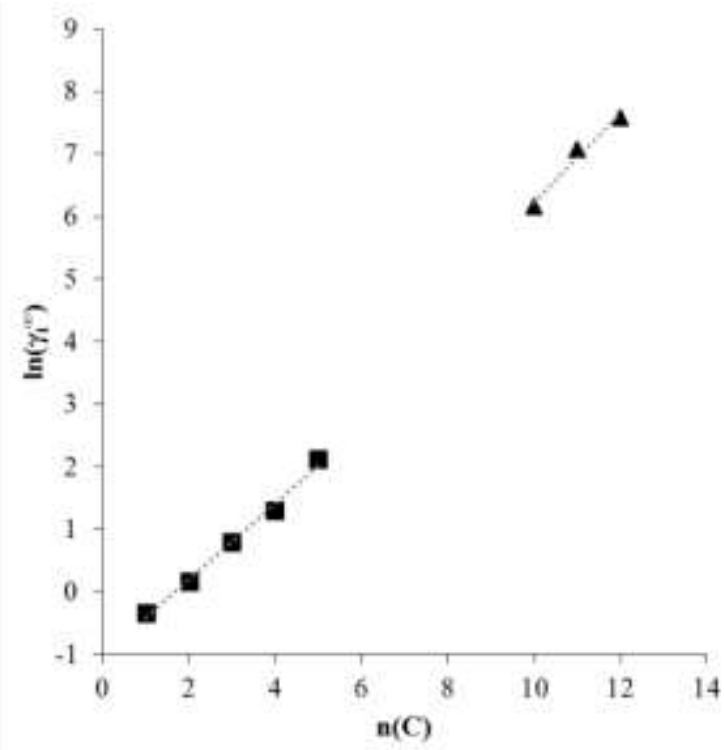

Figure S4. Values of $\ln \gamma_{i}^{\infty}$ of alkanes and alcohols in [DBNH][OAc] at $298 \mathrm{~K}$ as a function of carbon atoms number ( $\boldsymbol{\Delta}-$ alkanes, $\mathbf{\square}-$ alcohols $)$.

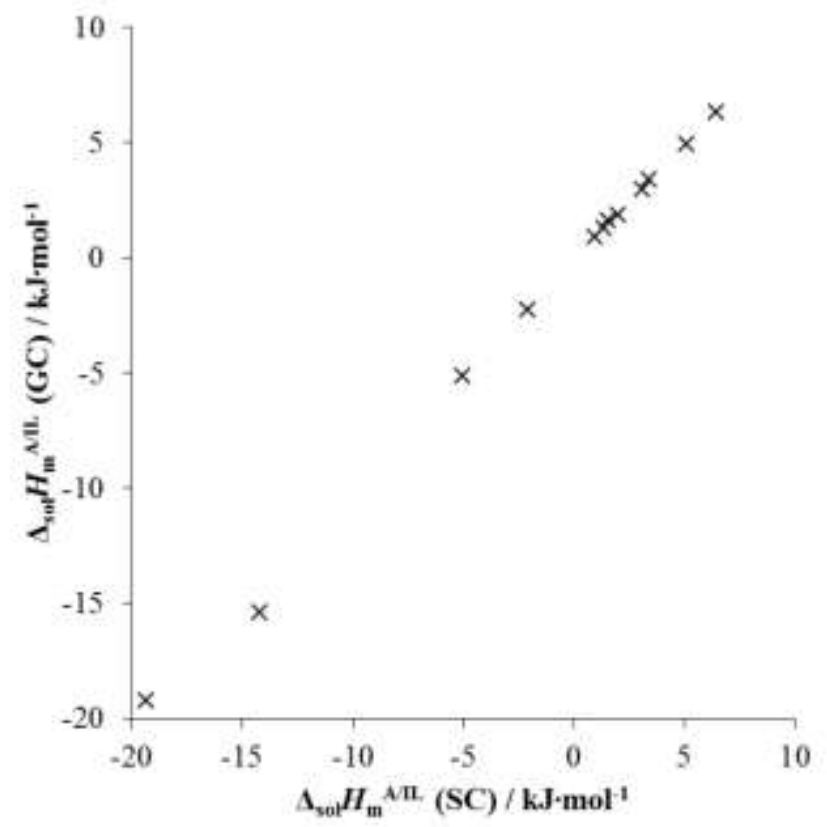

Figure S5. Comparison of solution enthalpies at infinite dilution of organic solutes in $[\mathrm{DBNH}][\mathrm{OAc}]$ determined by solution calorimetry (SC) and by gas-liquid chromatography (GC) methods. 


\section{REFERENCES}

[1] Suntsova, M. A. and Dorofeeva, O. V. J. Chem. Eng. Data 2016, 61, 313-329.

[2] Parr instrument company, Solution calorimeter 6755 operating instruction manual (593M), Online version available at (http://www.parrinst.com/products/oxygenbomb-calorimeters/6755-solution-calorimeter/documents/).

[3] Wagman, D. D.; Evans, W. H.; Parker, V.B.; Schumm, R. H.; Halow, I.; Bailey, S. M.; Churney, K. L.; Nuttall R. L. J. Phys. Chem. Ref. Data 1982, 11, Supplement 2.

[4] Richards, T. W.; Rowe, A. W. J. Am. Chem. Soc.1922, 44, 684-707.

[5] Ott, J. B. Thermochim. Acta 1997, 300, 255-281.

[6] Martin, J.F.; Andon, R.J.L. J. Chem. Thermodynam. 1982, 14, 679-688

[7] Richards, T. W.; Mair, B. J. J. Am. Chem. Soc. 1929, 51, 712-727.

[8] Cruickshank, A.J.B.; Windsor, M.L.; Young, C.L.; Proc. R. Soc. A 1966, 295, 259270.

[9] Grant, D.W.; Gas-Liquid Chromatography, van Nostrand Reinhold Company, London, 1971.

[10] Heintz, A.; Kulikov, D. V.; Verevkin, S. P. J. Chem. Eng. Data 2001, 46, 1526-1529.

[11] Heintz, A.; Vasiltsova, T. V.; Safarov, J.; Bich, E.; Verevkin, S.P. J. Chem. Eng. Data 2006, 51, 648-655.

[12] Reid, R. C.; Prausnitz, J. M.; Sherwood, T. K. The properties of gases and liquids, $3^{\text {rd }}$ ed., McGraw-Hill Chem. Eng. Series, New York, 1977.

[13] Prausnitz, J. M.; Lichtenthaler, R. N.; Azevedo, E. G. Molecular thermodynamics of fluid-phase equilibria, $2^{\text {nd }}$ ed., Prentice-Hall, New York, 1986.

[14] Safarov, J.; Verevkin, S.P.; Bich, E.; Heintz, A. J. Chem. Eng. Data 2006, 51, 518525.

[15] Ruzicka, K.; Majer, V. J. Phys. Chem. Ref. Data 1994, 23, 1-39.

[16] Steele, W. V. and Chirico, R. D. J. Phys. Chem. Ref. Data 1993, 22, 377-430.

[17] Ambrose, D.; Walton, J. Pure and Appl. Chem. 1989, 61, 1395-1403.

[18] Heintz, A.; Verevkin, S.P. J. Chem. Eng. Data 2005, 50, 1515-1519.

[19] Vasiltsova, T.V.; Verevkin, S.P.; Bich, E.; Heintz, A.; Bogel-Lukasik, R.; Domanska, U. J. Chem. Eng. Data 2006, 51, 213-218. 